\title{
Rural Leprosy Control Problems in Biafra and Central India: A Comparison*
}

\author{
T. F. DAVEY, c.B.E.
}

\section{INTRODUCTION}

It is not given to many leprologists, after long experience in one continent, to move to another and there become directly involved in developing leprosy control work at field level. Such is the experience of the writer, and after 18 months at Dichpalli, in the Telengana area of Andhra Pradesh, it is interesting to compare leprosy control problems here with those encountered in the territory around Uzuakoli, Biafra (E. Nigeria).

This is of more than academic interest, for leprosy is a disease of major importance both in India and in Nigeria. Substantial Government leprosy control programmes were introduced in both countries-in Nigeria in 1945 and in India in 1953. It is probably no accident that in basic approach the two programmes were very similar. Where personnel are concerned there appears in general to be little difference in education and training. In E. Nigeria a major reduction in the prevalence of leprosy occurred between 1940 and 1960, well attested by experienced observers (Davey et al., 1956; Davey, 1957). How far is this relevant to the situation in India? In this paper this question is examined in relation to the situation at ground level, as it confronts the paramedical worker and doctor in a rural area of Nizamabad District, with a population of 170,000 , resembling in population density and means of access many similar areas in Biafra.

The basic objectives of leprosy control are the same everywhere. At the risk of tedium they may be summarized as follows:

(1) Case finding: the aim being to discover

*Received for publication 15 August, 1969.
$100 \%$ of cases actually or potentially infective (bacteriologically positive by routine methods of examination), by a continuous process.

(2) Effective treatment of all cases, the first aim being to render all bacteriologicallypositive cases negative by appropriate chemotherapy; the second, to render $100 \%$ of all cases inactive, with patients fully rehabilitated into society.

(3) The protection of contacts, the aim being to reduce the number of new infections to zero, first by the treatment of established cases, but also by such ancillary methods as DDS prophylaxis, BCG inoculation, and the minimizing of contact between infective patients and those living in close proximity to them.

The objectives are clear. The discovery and application of ways to make them attainable is a very different matter. Even granted a well organized and internationally approved plan of operation by the Health Services, local factors in the last resort determine what can and what cannot be done. These are considered here under 3 headings: immunological environment, sociological determinants, and economic factors.

\section{IMMUNOLOGICAL ENVIRONMENT}

The entire range of clinical manifestations of leprosy seen in Nigeria has been encountered also at Dichpalli. There is no evidence for any important differences in the intrinsic nature of the leprosy seen in the two areas. At the same time, clinical variations occur which have an immediate bearing on leprosy control.

Leprosy in E. Nigeria was characterized by a high prevalence, often exceeding 40 per mile, with a low proportion of lepromatous cases 
(around $10 \%$ of the total), and a high proportion of mild, self-limiting infections (including indeterminate, maculo-anaesthetic, and minor tuberculoid types) with little tendency to break down to more serious forms of the disease in identifiable circumstances. In contrast, in this part of India the total prevalence found in intensive surveys is lower, varying between 5.0 and 40.0 per mile, leprosy following the usual focal variation in prevalence between one village and another. The apparent lower prevalence is accompanied by a lepromatous case-type index of 20 to $25 \%$, about double what it was in Nigeria. It should be noted, however, that whereas in surveys in Nigeria a population coverage of more than $90 \%$ was usual, in India we find that only by patient sustained effort can a figure higher than $70 \%$ be achieved. The missing $30 \%$ are certain to include a disproportionate number of leprosy infections, and it may very well be that there is little difference between the two areas in the actual prevalence of lepromatous leprosy.

At the same time, we find in India a decidedly higher prevalence than in Nigeria of unstable intermediate varieties of the disease, with a marked tendency to degenerate towards the lepromatous end of the spectrum. It is clear that many cases of lepromatous leprosy do not originate as such, but are the end result of this process of degeneration. This explains the frequent occurrence in lepromatous cases of severe nerve involvement with deformity, an infrequent finding in Nigeria.

Complex epidemiological and immunological factors must underlie this instability of leprosy in central India, though other endemic diseases and nutritional factors doubtless have a bearing on it. The subject will not be considered further here. For our purposes it suffices to note that leprosy in this Indian situation tends to be a more serious disease than in Nigeria, being generally less clear cut, more neurologically orientated, less predictable because more unstable, more productive of complications, and more prone to the various forms of reaction. On medical grounds, leprosy forces itself upon the attention of the Indian villager to a greater degree than was the case in E. Nigeria and thus fear of the disease is accentuated. Skilled medical supervision, important in Nigeria, is even more important in India, and calls for special attention in leprosy control planning.

\section{SOCIOLOGICAL DETERMINANTS}

The importance of careful medical and health planning is obvious in leprosy control, as indeed in the control of other communicable diseases. In India one is fortunate to be living in a country where a great deal of thought has been given to the planning of leprosy control and, with the economic resources available, it is difficult to envisage ways in which the National Leprosy Control Programme could have been bettered. In Nigeria, planning was more empirical, but when the need was evident, financial resources were provided by the Government to build up and extend on a national scale the plan of campaign already developed experimentally by voluntary agencies.

Leprosy is, however, unique in the importance of sociological factors in its control. More than one leprosy control programme has foundered through failure to appreciate this. The medical and health programme can only function if the people will accept it and co-operate in it. In the last resort the programme has to be determined by the sociological situation. From this standpoint there is considerable divergence between the two areas with which we are concerned. Leprosy is dreaded in both, but its control in E. Nigeria was a much simpler problem than is the case in India.

\section{Social solidarity}

Recent historical events have made plain to the world one of the remarkable features of Igbo Society in Biafra, namely the deep sense of community solidarity which is a national characteristic. At village level this means that family loyalty is part of a wider loyalty to the community as a whole. The relation between families is a blood relationship, all tracing their descent from a common ancestral family and being therefore conscious of an underlying 
unity which is never obliterated by temporary family differences. This feeling often extends to embrace whole groups of villages. Where leprosy control was concerned this provided a highly favourable situation. While much prejudice against leprosy had to be broken down, community solidarity provided the basis for rapid progress. If heads of families in council decided to co-operate in a programme proposed to them, public opinion was thereby determined and united action by the village or group of villages as a whole was expected to follow. It was this that underlay the success of intensive surveys. In the same way, because of their sense of communal solidarity, a high proportion of patients came forward for treatment without a great deal of persuasion.

In this part of India the situation is quite different. Cohesion in the village community is created, not by blood relationship, but by the functional needs of the community for services from one group or another. Unity, as seen in Biafra, does not exist. Basic loyalties are given, not to the village as such, but to the family and group within the village. Community solidarity has given place to family and craft solidarity, a situation in line with that applying to wide areas of the world outside the continent of Africa. This social situation is altogether less propitious for leprosy control than that prevailing in Biafra, presenting leprosy control workers in India with problems quite outside the range of experience of their Nigerian counterpart. A few illustrations will suffice:

(1) United action for leprosy control is rarely achieved, because the motive of ridding the whole village of leprosy has little appeal. The occasional keen village head can do a lot to help, but is liable to face opposition from some influential rival familv.

(2) In such a society it is of the greatest importance to every family to preserve its place in the hierarchy of status and influence. Leprosy is a grave threat to this and there is therefore every inducement to conceal the disease within the family as long as possible. Attendance at a leprosy clinic immediately stigmatizes the sufferer and his family. As a consequence regular attendance at clinics tends to be limited to the hard core of obvious cases, whose condition is already plain to all. In the same way, there is no enthusiasm for survey work, rather a grudging compliance with the wishes of the health authorities which falls short of the cooperation so necessary for the effective examination of all members of the household.

(3) The primary objective of people showing early signs of leprosy is all too often not the radical cure of the infection, but the covering up of its visible manifestations by as secret a method as possible. Most patients have recourse to practitioners of the traditional methods of medicine, whose medication often contains DDS in disguise. There is widespread taking of DDS without skilled medical control.

(4) The acceptability of the leprosy worker himself depends in no small degree on his own social background. Unless he comes from one of the higher strata, important sections of the village may be closed to him and he may even have difficulty in finding accommodation when his work demands his staying overnight.

If these experiences are related to the 3 basic objectives in leprosy control it immediately becomes apparent how profoundly the social framework affects the carrying out of leprosy control. Unless the importance of this is recognized, and methodology adapted to it, our objectives can remain an unattainable ideal.

\section{Dynamism in outlook}

In Nigeria, leprosy control was encouraged by the dynamic mood of the people. The country was opening up for the first time in history and there was a healthy readiness to accept change and development. In a number of places the leprosy workers were themselves the agents of this, and were the more acceptable because of it. That situation has no real counterpart in this area of India. Here, the whole process of development started earlier, and moves at a slower tempo. Hitherto, leprosy workers have had no opportunity to be pioneers in it. 


\section{Religious ideas}

In Nigeria traditional religious ideas did not favour participation by the community in leprosy control. Leprosy contaminated the sufferer and any who took his part. In practice, however, the effect of this was limited. Where the prevalence of leprosy exceeded about 30 per mile, as it did in many places, the disease tended to create an anxiety in the community which had greater potency towards accepting leprosy control measures than religious ideas had in the opposite direction. Here in India, theology may be different, but its practical outcome resembles that in Nigeria. With the general prevalence of leprosy frequently between 10 and 20 per mile, the impact of the disease on the community does not reach the point where anxiety is created. As everywhere else in the world, religious ideas may profoundly affect the readiness of the individual patient to co-operate in leprosy control, but community attitudes are more important. In this connection brief reference may be made to an important difference between Nigerian and Indian village society where physical examination is concerned, particularly of women. Through the strictures determined by society in India, it seems inevitable that some early infections in women must remain undetected. This problem was far less important in Nigeria.

\section{ECONOMIC FACTORS}

In E. Nigeria the economic situation had little if any direct influence on leprosy control methods. It was always possible for the peasant farmer or his wife to attend a weekly treatment clinic if they so desired. With the customary division of village occupations during the week it was usually possible to choose a day when everyone could be at home without much inconvenience, and thus mass survey work was facilitated.

In this area of India the seasons are not so kind and large sections of the community, with little or no land of their own, live at subsistence level, dependent on precarious daily earnings for the bare essentials of life. In such circumstances food has to take priority over the treatment of a chronic disease. Thus, for many patients, regular attendance at a weekly treatment clinic held during normal working hours is out of the question, and cannot be expected. The only possibility for patients to come together to a centre would mean completing all treatment before 9 a.m. Mass survey work meets the same basic problem.

\section{DISCUSSION AND CONCLUSIONS}

These facts highlight certain very important points where leprosy control planning is concerned.

\section{The important of sociological study}

While the social problems surrounding leprosy have been recognized for decades, it is still possible for them to be given insufficient weight in medical and health planning. Every leprosy planning committee needs the advice of sociologists as well as that of doctors, for in the long run it is the social factors which determine success or failure.

The need for adaptability in leprosy control method

Organization may demand uniformity of method. The local social and economic situation will not bend itself to suit the convenience of the leprosy worker. Indeed, it is the social and economic factors which set the limits within which he has to work. It is futile to hold treatment clinics at places and times convenient to the leprosy workers, if patients cannot or will not attend them. The primary objective is to get into the homes of patients, and our methods must be adapted to this end.

One helpful factor in India is the serious care which many patients display in carrying out meticulously the advice of the doctor. In such a situation it becomes possible to give patients DDS tablets at monthly or even 3-monthly intervals, and experience has shown that many will taken them regularly and correctly.

Social conditions have induced us in one area, where we have responsibility for leprosy control, to abandon leprosy clinics with failing 
attendance for an experimental period, and instead to aim at visiting every patient regularly in his home at least once every 3 months, replenishing his supply of DDS and submitting household contacts to regular examination, all the time maintaining contact with base hospital and physiotherapy services. Time formerly spent on visiting absentees is thus rationalized, and its frustration has gone. For the theoretical planner, such a technique invites condemnation. In practice it meets the case better than any possible alternative. It is quoted simply as an example of the need for experimentation and adaptation in our approach to the people.

\section{The need for a high standard in patient care}

In the face of the social and economic strictures with which the patient has to contend, it is not sufficient to go to him armed with nothing more than DDS. One element in success in Nigeria was the range of skilled services which were offered to patients, treatment of ulcers, medicine for other complaints, hospital care, physiotherapy, legal aid, and welfare work. These all helped towards cooperation and created relationships of trust between patient and worker which were really important. We were fortunate to be able to offer these things. If they mattered in a situation unusually propitious, they matter still more where circumstances are difficult. This pinpoints the need for the training of paramedical workers in relevant aspects of general medicine, for skilled direct supervision of paramedical workers, and the importance of providing hospital and other necessary facilities for patients.

The importance of integrating leprosy with general health services

So many of the problems confronting the leprosy worker derive from the "separateness" with which leprosy is regarded. While a separate organization for leprosy seems inevitable if there is to be any progress, the very existence of special workers and special facilities emphasizes in the mind of the general public that here is a disease of peculiar seriousness. Has not the time arrived for a re-orientation in our thinking, designed to give the whole range of general health workers, from specialist to junior village worker, an understanding of leprosy and a knowledge of it that will make possible everywhere the inclusion of leprosy sufferers within the general medical and health services as a normal and ordinary procedure? An intensive build-up in the leprosy education of professional workers is as important as is health education of the general public. Only as leprosy is "normalized" in this way will leprosy lose its terrors and the patient his mental suffering. In Nepal it is proposed to integrate leprosy into the general health services from the start. Other countries will look with deep interest at what happens there.

Comparisons are not always odious. If in this case they indicate the favourable circumstances in which leprosy workers operated in E. Nigeria, it was the dedication of many of these workers which achieved quick results. Wardekar (1968) has shown that the same dedication can achieve success in the more difficult situation which prevails in many places, provided it is allied with patience, ingenuity, and adaptability.

\section{SUMMARY}

A comparison between leprosy control problems in Eastern Nigeria and in Central India reveals the determining influence which social factors have in deciding the success or failure of a leprosy control programme. Stress is laid on the need for social studies, adaptability in applying methodology to local conditions, and also the need for high-class patient care. The importance of integrating leprosy work with the general health services is also

\section{REFERENCES}

DAVEY, T. F., Ross, C. M. and Nicholson, B. (1956). Leprosy; a changing situation in Eastern Nigeria. Br. med. .J. $i i, 65$.

DAVEY, T. F. (1957). Decline of leprosy in a group of Nigerian villages between 1941 and 1956. Int. .J. Lepr. 25, 329.

WARDEKAR, R. v. (1968). Effect of sulphone on prevalence of leprosy. Paper No. 77, Ninth International Leprosy Congress. Int. .J. Lepr. (in press). 